Note

\title{
The revised NMR chemical shift data of carrageenans
}

\author{
Fred van de Velde, ${ }^{\mathrm{a}, \mathrm{b}, *}$ Leonel Pereira ${ }^{\mathrm{c}}$ and Harry S. Rollema ${ }^{\mathrm{b}}$ \\ ${ }^{\mathrm{a}}$ Wageningen Centre for Food Sciences, PO Box 557, 6700 AN Wageningen, The Netherlands \\ ${ }^{\mathrm{b}}$ NIZO food research, Product Technology Department, Kernhemseweg 2, PO Box 20, 6710 BA Ede, The Netherlands \\ ${ }^{\mathrm{c}}$ Department of Botany, University of Coimbra, Arcos do Jardim-3000 Coimbra, Portugal \\ Received 5 March 2004; accepted 14 July 2004 \\ Available online 11 August 2004
}

\begin{abstract}
A new set of ${ }^{13} \mathrm{C}$ and ${ }^{1} \mathrm{H}$ NMR chemical shifts of most common carrageenan types is given relative to DSS as the internal standard according to the IUPAC recommendations. Moreover, the chemical shifts of characteristic signals for pyruvate acetal and floridean starch are reported. Additionally, chemical shifts of common internal standards, such as methanol, DMSO and acetone, were measured at different temperatures and $\mathrm{pH}$ values.

(c) 2004 Elsevier Ltd. All rights reserved.
\end{abstract}

Keywords: Carrageenan; Hybrids; NMR spectroscopy; Structure analysis; Chemical shift data

Carrageenans represent one of the major texturising ingredients in the food industry. ${ }^{1}$ Carrageenan is a generic name for a family of linear, sulfated galactans, obtained by extraction from certain species of marine red algae (Rhodophyta). They are composed of alternating 3-linked $\beta$-D-galactopyranose (G-units) and 4-linked $\alpha$-D-galactopyranose (D-units) or 4-linked 3,6-anhydro- $\alpha$-D-galactopyranose (DA-units), forming the disaccharide repeating unit of carrageenans (see Fig. 1). The letter codes in Figure 1 refer to the nomenclature developed by Knutsen et al. ${ }^{2}$ Since natural carrageenan is a mixture of nonhomologous polysaccharides, the term disaccharide repeating unit refers to the idealised structure.

The sulfated galactans are classified according to the presence of the 3,6-anhydro bridge on the 4-linked galactose residue and the position and number of sulfate groups. The most common types of carrageenan are traditionally identified by a Greek prefix. The three commercially most important carrageenans are called $1-, \quad \kappa-$ and $\lambda$-carrageenan, and the corresponding IUPAC-inspired names and letter codes are carrageenose 2,4'-disulfate (G4S-DA2S), carrageenose 4'-sulfate

\footnotetext{
* Corresponding author. Tel.: +31-318-659-582; fax: +31-318-650-400; e-mail: fred.van.de.velde@nizo.nl
}

(G4S-DA) and carrageenan 2,6,2'-trisulfate (G2SD2S,6S). In addition to these three major carrageenan types, two other types, called $\mu$ - and $v$-carrageenan (letter code G4S-D6S and G4S-D2S,6S, respectively), are often encountered in commercial carrageenan samples and are the biological precursors of, respectively, $\kappa$ - and i-carrageenan.

Since natural carrageenans are mixtures of different sulfated polysaccharides, their composition differs from batch to batch. Therefore, the quantitative analysis of carrageenan batches is of greatest importance for both ingredient suppliers and food industries to ensure ingredient quality. From the pioneering work of Usov and co-workers, ${ }^{3,4}$ NMR spectroscopy is nowadays the preferred technique to determine and quantify the composition of carrageenan batches. ${ }^{5}$ Starting from the early work of Usov and co-workers, chemical shifts of carrageenan resonances are generally converted to values relative to tetramethylsilane (TMS) via an internal dimethyl sulfoxide (DMSO) or methanol $(\mathrm{MeOH})$ standard. $^{3,6-8}$ The use of DMSO or $\mathrm{MeOH}$ as internal standards resulted in a generally accepted set of chemical shifts for different types of carrageenans as summarised by van de Velde et al. ${ }^{5}$ However, to convert chemical shifts from aqueous internal DMSO or $\mathrm{MeOH}$ to values relative to TMS is not obvious, as TMS is only sparingly soluble in highly polar solvents such as water 


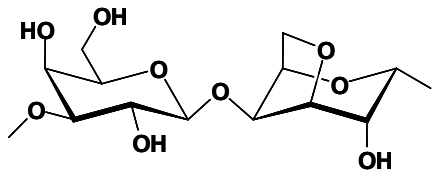

G $\beta$-carrageenan
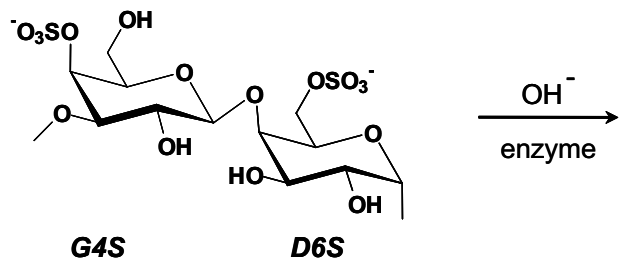

$\mu$-carrageenan
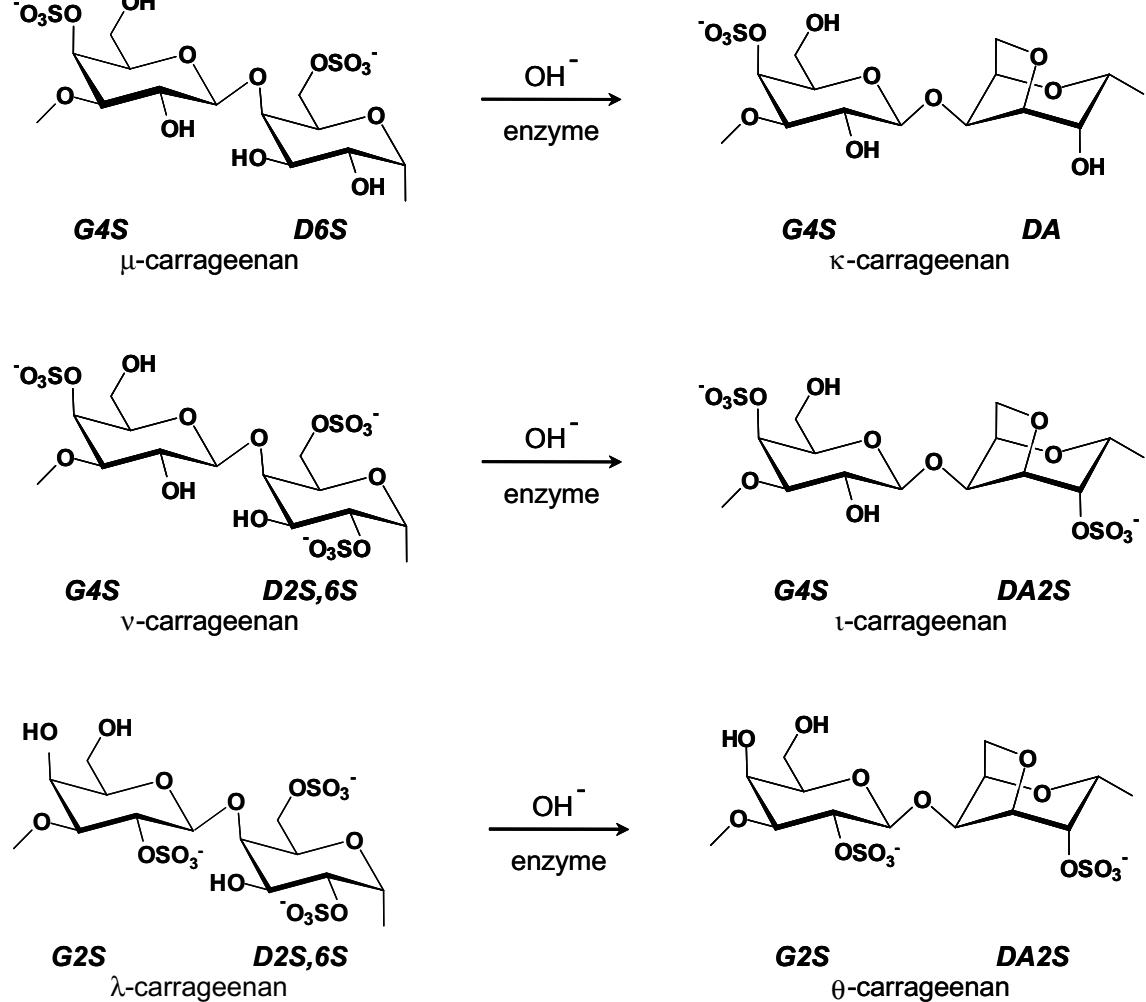

К-carrageenan

$\theta$-carrageenan

$D A$

v-carrageenan

t-carrageenan

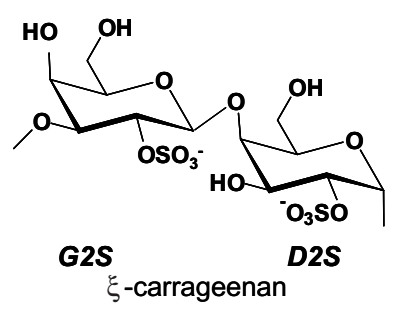

Figure 1. Schematic representation of the different structures of the repeating units of carrageenans. The letter codes refer to the nomenclature of Knutsen et al. ${ }^{2}$

or $\mathrm{D}_{2} \mathrm{O}$. Therefore, the IUPAC commission for molecular structure and spectroscopy recently recommended the use of 2,2-dimethyl-2-silapentane-3,3,4,4,5,5- $d_{6}-5$ sulfonate sodium salt (DSS) as the primary reference for both ${ }^{1} \mathrm{H}$ and ${ }^{13} \mathrm{C}$ NMR spectroscopy in highly polar solvents. For most purposes the difference between DSS and TMS when dissolved in the same solvent are negligible, and, therefore, the data from DSS and TMS scales may be validly compared without correction. ${ }^{9}$

However, application of the IUPAC recommendations in NMR spectroscopy of carrageenans results in changed chemical shifts for all common carrageenan types. Pereira et al. ${ }^{10}$ reported chemical shift values relative to DSS for $\kappa$ - and 1 -carrageenan that are $2.5 \mathrm{ppm}$ larger than those reported by Usov. ${ }^{3}$ Therefore, we studied the application of DSS as an internal standard for NMR spectroscopy of carrageenans in more detail.

In this work, both ${ }^{13} \mathrm{C}$ and ${ }^{1} \mathrm{H}$ NMR spectra of representative carrageenan samples containing the most common repeating units, for example, $\kappa$ (kappa)-, 1 (iota)-, $\lambda$ (lambda)-, $\mu$ (mu)-, $v$ (nu)-, $\theta$ (theta)-, $\beta$ (beta)- and $\xi$ (ksi)-carrageenan were recorded. The chemical shifts of all carbon atoms as well as the anomeric protons are reported relative to DSS internal standard $(\delta=0.000 \mathrm{ppm})$ 
according to IUPAC recommendations, ${ }^{9}$ providing the scientific community with a new set of chemical shift data for different carrageenan types.

\section{Discussion}

First of all ${ }^{13} \mathrm{C}$ and ${ }^{1} \mathrm{H}$ NMR spectra of mixtures of different internal standards, for example, DSS, DMSO, $\mathrm{MeOH}$, acetone and 3-(trimethylsilyl)propionic-2,2,3,3$d_{4}$ acid sodium salt (TSP, as an alternative for DSS ${ }^{9}$ ), were recorded at three temperatures $\left(24,45\right.$ and $\left.65^{\circ} \mathrm{C}\right)$ in $\mathrm{D}_{2} \mathrm{O}$ containing $20 \mathrm{mM}$ phosphate adjusted to the following $\mathrm{pH}$ values: $\mathrm{pH}$ 5.5, 7.2, 9.7 and 11.8. Chemical shifts of the different internal standards are given in Table 1 . According to the IUPAC recommendations, DSS is set at a chemical shift of $0 \mathrm{ppm}$ for all temperatures and $\mathrm{pH}$ values. ${ }^{9}$

Measured within the $\mathrm{pH}$ range from $\mathrm{pH} 5.5$ to 11.7 , the chemical shifts of the internal standards, TSP, DMSO and $\mathrm{MeOH}$ were $\mathrm{pH}$ insensitive. Although acetone showed good signal at pH 5.5 and 7.2, the intensity of this signal dropped dramatically at higher $\mathrm{pH}$ values. This is probably due to ketone-enol rearrangements. Therefore, acetone is not the internal reference of choice at higher $\mathrm{pH}$ values. Temperature dependency of the chemical shift of the internal standards was observed in the ${ }^{13} \mathrm{C}$ spectra for DMSO. The chemical shift of the DMSO resonance in the ${ }^{13} \mathrm{C}$ spectra shifted from $41.29 \mathrm{ppm}$ at $24^{\circ} \mathrm{C}$ to $41.53 \mathrm{ppm}$ at $65^{\circ} \mathrm{C}$.

TSP has a chemical shift of $\delta=-0.18\left({ }^{13} \mathrm{C}\right)$ and $\delta=-0.017\left({ }^{1} \mathrm{H}\right)$ that allows the use of TSP as an alternative for DSS. The measured ${ }^{13} \mathrm{C}$ NMR chemical shifts of DMSO $(\delta=41.53)$ and $\mathrm{MeOH}(\delta=51.43)$ are significantly different from those reported and used by Usov et al., ${ }^{6}$ respectively, $\delta=39.45$ and $\delta=50.12$ for DMSO and $\mathrm{MeOH}$. This difference explains for the greater part the chemical shift differences observed by Pereira et al. ${ }^{10}$ Usov et al. ${ }^{6}$ already mentioned in their comments on chemical shift calculation a systematic discrepancy (up to $1 \mathrm{ppm}$ ) in chemical shifts reported by different authors. However, in our opinion the chemical shifts of DMSO and $\mathrm{MeOH}$ reported are measured in apolar solvent to allow the use of TMS as internal standard and, thereby, are significantly different from those measured in aqueous solution.

Furthermore, both ${ }^{13} \mathrm{C}$ and ${ }^{1} \mathrm{H}$ NMR spectra were recorded for relevant carrageenan samples containing the most common carrageenan repeating units, for example, $\kappa-, ~ 1-, \lambda-, \mu-, \nu-, \theta-, \beta$ - and $\xi$-carrageenan. Assignment of the resonances in the NMR spectra of the common carrageenan types was based on spectra and data summarised in literature. ${ }^{5}$ For the $\xi$-carrageenan ${ }^{13} \mathrm{C}$ NMR spectrum, only a few resonances are assigned in literature. ${ }^{11} \mathrm{~A}$ detailed study on the interpretation of both the ${ }^{13} \mathrm{C}$ and ${ }^{1} \mathrm{H}$ NMR spectra of a $\xi / \theta$-hybrid carrageenan is currently carried out and the results will be published separately (Usov, A. I.; Shashkov, A. S.; Rollema, H. S.; Pereira, L.; Van de Velde, F. Carbohydr. Res., in preparation). The chemical shift data obtained in the current study are summarised in, respectively, Tables 2 and 3. The ${ }^{13} \mathrm{C}$ NMR chemical shifts of $\kappa$ - and $\mathrm{l}$-carrageenan relative to DSS are in good agreement with those reported in literature, ${ }^{10}$ although they were measured under different conditions. Generally, the chemical shifts given in Table 2 are larger (on average $2.1 \mathrm{ppm}$ ) than those summarised by Van de Velde et al. ${ }^{5}$ This difference is equal to the difference between the measured chemical shift of DMSO relative to DSS and the chemical shift of DMSO reported by Usov et al. ${ }^{6}$ The ${ }^{1} \mathrm{H}$ NMR chemical shifts of the $\alpha$-anomeric protons of carrageenans (Table 3) are only slightly different from those reported in literature. $^{5,12}$

In addition to the common carrageenan repeating units, the analysed carrageenan samples contained some minor constituents and contaminants that are frequently encountered in carrageenan batches. Pyruvic acid is a common component of many complex carrageenans. It forms a cyclic acetal at positions 4 and 6 of 3-linked galactose residues. This substituent can be identified by characteristic signals of its carbons together with specific substitution effects on the corresponding carbon atoms of 3-linked D-galactose. ${ }^{5,11,13}$ Relative to DSS the ${ }^{13} \mathrm{C}$ NMR chemical shifts of these characteristic

Table 1. Chemical shifts for common internal standards for NMR spectroscopy in aqueous systems

\begin{tabular}{|c|c|c|c|}
\hline \multirow[t]{2}{*}{ Compound abbr. } & \multicolumn{2}{|c|}{ Chemical shift $(\mathrm{ppm})^{\mathrm{a}}$} & \multirow[t]{2}{*}{ Compound chemical name } \\
\hline & ${ }^{13} \mathrm{C}$ & ${ }^{1} \mathrm{H}$ & \\
\hline DSS & 0.000 & 0.000 & 2,2-Dimethyl-2-silapentane-3,3,4,4,5,5- $d_{6}$-5-sulfonate sodium salt \\
\hline TSP & -0.18 & -0.017 & 3-(Trimethylsilyl)propionic-2,2,3,3- $d_{4}$ acid sodium salt \\
\hline $\mathrm{MeOH}$ & 51.43 & 3.337 & Methanol \\
\hline DMSO & $41.53^{\mathrm{b}}$ & 2.696 & Dimethyl sulfoxide \\
\hline Acetone $^{c}$ & 32.69 & 2.208 & Acetone \\
\hline
\end{tabular}

\footnotetext{
${ }^{\mathrm{a}}$ Recorded in $\mathrm{D}_{2} \mathrm{O}$ containing $\mathrm{NaH}_{2} \mathrm{PO}_{4}$ and $\mathrm{Na}_{2} \mathrm{HPO}_{4}\left(20 \mathrm{mM}\right.$ phosphate; pH 7.2) at $65^{\circ} \mathrm{C}$. Constant chemical shifts measured between 24 and $65^{\circ} \mathrm{C}$ and between $\mathrm{pH} 5.5$ and $\mathrm{pH} 11.8$, with the exception of DMSO where a slight temperature dependence was observed, and acetone, which is not applicable at high $\mathrm{pH}$ (see text).

${ }^{\mathrm{b}}$ Slight temperature dependency observed ranging from a chemical shift of $41.29 \mathrm{ppm}$ at $24^{\circ} \mathrm{C}$ to $41.53 \mathrm{ppm}$ at $65^{\circ} \mathrm{C}$.

${ }^{\mathrm{c}}$ Only valid at pH5.5 and 7.2.
} 
Table 2. ${ }^{13} \mathrm{C}$ NMR chemical shifts for the most common carrageenan structural units ${ }^{\mathrm{a}}$

\begin{tabular}{|c|c|c|c|c|c|c|c|}
\hline \multirow[t]{2}{*}{ Carrageenan } & \multirow[t]{2}{*}{ Unit $^{\mathrm{b}}$} & \multicolumn{6}{|c|}{ Chemical shift (ppm) relative to DSS as internal standard } \\
\hline & & C-1 & $\mathrm{C}-2$ & C-3 & $\mathrm{C}-4$ & C-5 & C-6 \\
\hline \multirow[t]{2}{*}{$\beta$ (beta) } & $\mathrm{G}$ & 104.81 & 71.72 & 82.58 & 68.56 & 77.55 & 63.49 \\
\hline & DA & 96.81 & 72.40 & 81.64 & 80.33 & 79.26 & 71.72 \\
\hline \multirow[t]{2}{*}{ l (iota) } & G4S & 104.43 & 71.53 & 79.06 & 74.34 & 77.04 & 63.52 \\
\hline & DA2S & 94.29 & 77.15 & 80.04 & 80.55 & 79.29 & 72.02 \\
\hline \multirow[t]{2}{*}{ к (kappa) } & G4S & 104.70 & 71.72 & 80.98 & 76.25 & 77.00 & 63.49 \\
\hline & $\mathrm{DA}$ & 97.34 & 72.11 & 81.41 & 80.54 & 79.07 & 71.72 \\
\hline \multirow[t]{2}{*}{$\lambda$ (lambda) } & G2S & 105.61 & 79.61 & 77.99 & 66.35 & 76.51 & 63.45 \\
\hline & $\mathrm{D} 2 \mathrm{~S}, 6 \mathrm{~S}$ & 93.85 & 77.04 & 71.76 & 82.61 & 70.89 & 70.25 \\
\hline \multirow[t]{2}{*}{$\mu(\mathrm{mu})^{\mathrm{c}}$} & G4S & 107.00 & 72.69 & 80.54 & 76.25 & 77.1 & 63.48 \\
\hline & D6S & 100.26 & 70.7 & 72.8 & 81.40 & 70.5 & 69.89 \\
\hline \multirow[t]{2}{*}{$v(n u)$} & G4S & 106.96 & 72.40 & 82.42 & $73.36^{\mathrm{d}}$ & 77.15 & 63.58 \\
\hline & $\mathrm{D} 2 \mathrm{~S}, 6 \mathrm{~S}$ & 100.53 & 78.58 & 70.37 & 82.13 & 70.37 & 70.02 \\
\hline \multirow[t]{2}{*}{$\theta(\text { theta })^{\mathrm{e}}$} & G2S & 102.57 & 79.8 & 79.4 & 69.97 & 77.05 & 63.38 \\
\hline & DA2S & 97.81 & 77.05 & 79.6 & 81.75 & 79.2 & 72.35 \\
\hline \multirow[t]{2}{*}{$\xi(\mathrm{ksi})^{\mathrm{f}}$} & $\mathrm{G} 2 \mathrm{~S}$ & 105.44 & & & 66.92 & & \\
\hline & D2S & 94.94 & & & & & \\
\hline
\end{tabular}

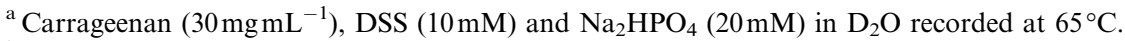

${ }^{\mathrm{b}}$ Codes refer to the nomenclature developed by Knutsen et al. ${ }^{2}$

${ }^{\mathrm{c}}$ Chemical shifts given with one decimal place are obtained from literature and corrected with the offset calculated for the chemical shifts of the anomeric carbon atoms. ${ }^{12}$

${ }^{\mathrm{d}}$ Chemical shift differs from the value given in the literature. ${ }^{12}$

${ }^{\mathrm{e}}$ Chemical shifts given with one decimal place are recalculated from literature; ${ }^{18}$ moreover, they may be interchanged. TSP is used as the internal standard; however, chemical shifts are given relative to DSS.

${ }^{\mathrm{f}}$ Only a few resonances of the $\xi$-carrageenan spectrum are assigned in literature. ${ }^{11}$ A detailed study on the interpretation of the NMR spectra of a $\xi / \theta$ hybrid carrageenan is currently in progress and the results will be published separately (Usov, A. I.; Shashkov, A. S.; Rollema, H. S.; Pereira, L.; Van de Velde, F. Carbohydr. Res., in preparation). TSP is used as the internal standard; however, chemical shifts are given relative to DSS.

Table 3. Chemical shifts (ppm) of the $\alpha$-anomeric protons of carrageenans referred to DSS as internal standard at $0 \mathrm{ppm}^{\mathrm{a}}$

\begin{tabular}{lll}
\hline Carrageenan & Monosaccharide $^{\mathrm{b}}$ & Chemical shift $(\mathrm{ppm})$ \\
\hline$\beta$ (beta) & DA & 5.074 \\
( (iota) & DA2S & 5.292 \\
$\kappa$ (kappa) & DA & 5.093 \\
$\lambda$ (lambda) & D2S,6S & 5.548 \\
$\nu(\mathrm{nu})$ & D2S,6S & 5.501 \\
$\mu(\mathrm{mu})$ & D6S & 5.238 \\
\hline
\end{tabular}

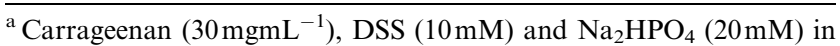
$\mathrm{D}_{2} \mathrm{O}$ recorded at $65^{\circ} \mathrm{C}$.

${ }^{\mathrm{b}}$ Codes refer to the nomenclature developed by Knutsen et al. ${ }^{2}$

signals are $27.61,103.55$ and $177.96 \mathrm{ppm}$ for, respectively, the methyl, acetal and carboxyl carbon atoms. The pyruvic acid acetals are also detected in the ${ }^{1} \mathrm{H}$ NMR spectra by the methyl proton resonances with a chemical shift of $1.44 \mathrm{ppm}$ relative to DSS. In addition to the methyl signal, characteristic signals in the anomeric proton region are observed at 5.30 and $5.49 \mathrm{ppm}$. Small amounts of 3-linked 6-O-methyl-Dgalactose residues were found in $\kappa$-carrageenan from
Kappaphycus alvarezii ${ }^{14}$ and in several other polysaccharides. ${ }^{8}$ The specific signal for $\mathrm{OMe}$ is found at a chemical shift relative to DSS of $61.14 \mathrm{ppm}$ in the ${ }^{13} \mathrm{C}$ NMR spectrum.

Floridean starch, a branched $(1 \rightarrow 4,1 \rightarrow 6)$ - $\alpha$-D-glucan structurally related to plant amylopectins and animal glycogens, is a storage polysaccharide of red algae. It is soluble in water and can accompany carrageenans in the extraction and precipitation steps. The presence of floridean starch can be confirmed by the well-known set of signals of 4-linked $\alpha$-D-glucopyranose residues in the ${ }^{13} \mathrm{C}$ NMR spectrum. ${ }^{5,15,16}$ In carrageenan ${ }^{13} \mathrm{C}$ NMR spectra, floridean starch signals are detected at chemical shifts relative to DSS at 102.55, 74.34 and 74.04 ppm for, respectively, the C-1, C-2 and C-5 carbon atoms. In the ${ }^{1} \mathrm{H}$ NMR spectra, floridean starch is detected by the signal of the anomeric proton of the $\alpha$-(1 $\rightarrow 4)$-linked D-glucopyranosyl moiety at $5.35 \mathrm{ppm}$. The resonance of the anomeric proton of the $\alpha$-(1 $\rightarrow 6)$-linked D-glucopyranosyl appears at a chemical shift of $0.39 \mathrm{ppm}$ upfield. ${ }^{16}$ 2-Propanol is generally applied to precipitate carrageenans from the extraction 
liquid. ${ }^{1}$ Therefore, 2-propanol can be observed in the NMR spectra of carrageenan batches. In the ${ }^{1} \mathrm{H}$ NMR spectra 2-propanol gives a characteristic triplet at $1.169 \mathrm{ppm}$. In the ${ }^{13} \mathrm{C}$ NMR spectra the methyl carbon of 2-propanol is detected at $26.38 \mathrm{ppm}$.

In conclusion, we report here a new set of chemical shifts for most common types of carrageenan repeating units relative to DSS as the internal standard as recommended by the IUPAC. ${ }^{9}$ In addition to the chemical shifts of carrageenan repeating units, the chemical shifts of minor substituent and contaminants of carrageenan batches are reported.

\section{Experimental}

\subsection{Carrageenan samples}

Alkaline- and water-extracted carrageenan samples from the following species were used to record the NMR spectra: Betaphycus gelatinum, Chondracanthus teedei, Eucheuma denticulatum, Gigartina skottsbergii, Kappaphycus alvarezii, Sarconema scinaioides. To reduce the viscosity of the NMR samples, carrageenan samples were first sonicated according the following procedure. Carrageenan $\left(250 \mathrm{mg} ; 5 \mathrm{mgmL}^{-1}\right.$ ) was dissolved in phosphate buffer $\left(50 \mathrm{~mL} ; 20 \mathrm{mM} \mathrm{Na} \mathrm{NPO}_{4}\right)$ at $80^{\circ} \mathrm{C}$ for $30 \mathrm{~min}$ and allowed to cool to room temperature. This solution was sonicated for three times $30 \mathrm{~min}$ in melting ice (Heat Systems XL 2020 sonicator, $12 \mathrm{~mm}$ tip, power $475 \mathrm{~W}$, frequency $20 \mathrm{kHz}$ ), the solution was centrifuged at elevated temperature (above the gelation temperature) to remove insoluble material. The sonicated solutions were dialysed against phosphate buffer $(20 \mathrm{mM}$ $\left.\mathrm{Na}_{2} \mathrm{HPO}_{4} ; 3 \times 2 \mathrm{~L}\right)$, water $(1 \times 2 \mathrm{~L})$ and lyophilised.

\subsection{NMR spectroscopy of carrageenans}

NMR samples were prepared by dissolving the sonicated carrageenans $\left(30 \mathrm{mgmL}^{-1}\right)$ in $\mathrm{D}_{2} \mathrm{O}$ containing $20 \mathrm{mM}$ $\mathrm{Na}_{2} \mathrm{HPO}_{4}$ and $10 \mathrm{mM}$ internal standard (DSS). ${ }^{1} \mathrm{H}$ NMR spectra were taken at $65^{\circ} \mathrm{C}$ on a Bruker DRX500 spectrometer operating at $500.13 \mathrm{MHz}$. Typically 64 scans were taken with an interpulse delay of $5 \mathrm{~s}\left(\mathrm{~T}_{1}\right.$ values for the resonances of the anomeric protons of $\kappa$ - and i-carrageenan are smaller than $1.5 \mathrm{~s}$ ). ${ }^{13} \mathrm{C}$ NMR spectra were recorded at $65^{\circ} \mathrm{C}$ on a Bruker DRX500 spectrometer operating at $125.76 \mathrm{MHz}$ essentially as described elsewhere. ${ }^{17}$ Chemical shifts $(\delta)$ are relative to internal DSS standard $(\delta=0.000 \mathrm{ppm}$ for both ${ }^{1} \mathrm{H}$ and ${ }^{13} \mathrm{C}$ according to the IUPAC recommendations $^{9}$ ). Assignments of the NMR spectra were based on spectra and data summarised by Van de Velde et al. ${ }^{5}$

\subsection{Internal standards}

Phosphate-buffered $\mathrm{D}_{2} \mathrm{O}$ solutions of different $\mathrm{pH}$ values were prepared by dissolving either $\mathrm{NaH}_{2} \mathrm{PO}_{4}(20 \mathrm{mM}$; pH 5.5), a mixture of $\mathrm{NaH}_{2} \mathrm{PO}_{4}$ and $\mathrm{Na}_{2} \mathrm{HPO}_{4}(20 \mathrm{mM}$ phosphate; pH 7.2), $\mathrm{Na}_{2} \mathrm{HPO}_{4}(20 \mathrm{mM} ; \mathrm{pH} 9.7)$, or a mixture of $\mathrm{Na}_{2} \mathrm{HPO}_{4}$ and $\mathrm{NaOH}(20 \mathrm{mM}$ phosphate; $\mathrm{pH} 11.8$ ) in $\mathrm{D}_{2} \mathrm{O} . \mathrm{pH}$ values given throughout this paper are the $\mathrm{pH}$ readings of our electrode. Mixtures of the different internal standards were prepared by dissolving DSS $(0.15 \mathrm{M})$, TSP $(0.28 \mathrm{M}), \mathrm{MeOH}(0.85 \mathrm{M})$, DMSO $(0.50 \mathrm{M})$ and acetone $(0.45 \mathrm{M})$ in the $\mathrm{D}_{2} \mathrm{O}$ /phosphate solutions. NMR spectra were taken at 24,45 and $65^{\circ} \mathrm{C}$ on a Bruker DRX500 spectrometer.

\section{References}

1. Van de Velde, F.; De Ruiter, G. A. In Biopolymers Vol. 6: Polysaccharides II: Polysaccharides from Eukaryotes; Steinbüchel, A., DeBaets, S., VanDamme, E. J., Eds.; Wiley-VCH: Weinheim, 2002; Vol. 6, pp 245-274.

2. Knutsen, S. H.; Myslabodski, D. E.; Larsen, B.; Usov, A. I. Bot. Mar. 1994, 37, 163-169.

3. Usov, A. I. Bot. Mar. 1984, 27, 189-202.

4. Yarotsky, S. V.; Shashkov, A. S.; Usov, A. I. Bioorg. Khim. 1977, 4, 1135-1137.

5. Van de Velde, F.; Knutsen, S. H.; Usov, A. I.; Rollema, H. S.; Cerezo, A. S. Trends Food Sci. Technol. 2002, 13, 73-92.

6. Usov, A. I.; Yarotsky, S. V.; Shashkov, A. S. Biopolymers 1980, 19, 977-990.

7. Miller, I. J.; Blunt, J. W. Bot. Mar. 2000, 43, 263271.

8. Chiovitti, A.; Bacic, A.; Craik, D. J.; Munro, S. L. A.; Kraft, G. T.; Liao, M.-L. Carbohydr. Res. 1998, 305, 243-252.

9. Harris, R. K.; Becker, E. D.; CabralDeMenezes, S. M.; Goodfellow, R.; Granger, P. Pure Appl. Chem. 2001, 73, 1795-1818.

10. Pereira, L.; Sousa, A.; Coelho, H.; Amado, A. M.; Ribeiro-Claro, P. J. A. Biomol. Eng. 2003, 20, 223-228.

11. Falshaw, R.; Furneaux, R. H. Carbohydr. Res. 1995, 276, 155-165.

12. Ciancia, M.; Matulewicz, M. C.; Finch, P.; Cerezo, A. S. Carbohydr. Res. 1993, 238, 241-248.

13. Chiovitti, A.; Bacic, A.; Craik, D. J.; Kraft, G. T.; Liao, M.-L.; Falshaw, R.; Furneaux, R. H. Carbohydr. Res. 1998, 310, 77-83.

14. Bellion, C.; Brigand, G.; Prome, J.-C.; Bociek, D. W. S. Carbohdr. Res. 1983, 119, 31-48.

15. Colson, P.; Jennings, H. J.; Smith, J. C. P. J. Am. Chem. Soc. 1974, 96, 8081-8087.

16. Knutsen, S. H.; Grasdalen, H. Bot. Mar. 1987, 30, 497-505.

17. Van de Velde, F.; Peppelman, H. A.; Rollema, H. S.; Tromp, R. H. Carbohydr. Res. 2001, 331, 271-283.

18. Falshaw, R.; Furneaux, R. Carbohydr. Res. 1994, 252, 171-182. 